\title{
Analysis of Currency Internationalization with Trade Structure
}

\author{
Zhang Xuefeng \\ School of Economics and Management \\ North China University of Technology \\ Beijing, China \\ E-mail: zxf511@163.com
}

\begin{abstract}
Degree of internationalization of currency can be reflected by the trade structure at the denominating level. This paper established a three-sector macroeconomic model with representative households, enterprises and governments. We introduce import and export trade settlement structure on representative household's revenue and expenditure, dividing enterprises into trade enterprises and non-tradable enterprises, and finally we analyze the influences of the changes of economic subject's main variables on the structure of trade settlement in an equilibrium market. The conclusions of this study are as follows: if the real exchange rate of foreign currency is greater than 1, the growth of the three variables including attractiveness of foreign goods, the elasticity of capital output and the government expenditure will deepen the internationalization of the currency; if the actual exchange rate is less than 1, the three variables take effects on it in a perverse way. In this research the possible reasons of the internationalization of the currency are discussed from the theoretical level, in the end we take RMB for example to explain the process of currency internationalization.
\end{abstract}

Keywords-Trade settlement structure; Macroeconomic model; currency internationalization

\section{INTRODUCTION}

The internationalization of currency is an important economic phenomenon. The general scholars argue that the internationalization of currency refers to that a currency is accepted by the foreign individuals or institutions as a medium of exchange, a unit of account and a store of value. Currency internationalization is defined by Cohen[1]at first: an international currency is a currency which performs its monetary function besides its issuing country; Hartmann [2] takes official and private usage into account when referring to the functions of medium of exchange, unit of account and store of value, and refined the definition of international currency; Pollard[3]argued that the three functions are interactive, and there is no internal order. And the measure of the degree of currency internationalization is a problem. Eichengreen and Mathieson[4] argued that the international status of the currency is determined by factors such as trade object, external debt structure and exchange rate arrangement. Ken[5][6]measures the international status of the currency by the ratio of the volume of transactions between one country's currency and foreign currencies to the total volume of transactions; Lim[7]measured the degree of internationalization of currency

Supported by the North China University of Technology outstanding young teacher training program, funded Beijing Social Science

Foundation(Grant No.16LJC008) and Foundation for The Excellent Youth

Scholars of Beijing (Grant No.2016000020124G021) by the ratio of the total amount of bonds denominated in international currencies; Chin and Frankel[8]measure the degree of internationalization of the currency by the economic aggregate of the issuing country, inflation, exchange rate and financial market development; Thimann[9]constructed a "monetary global status" indicator, which not only includes the economic scale also takes the economic structure into account. Xiaoyan Bai[10]found that different functions play the leading role in different stages in the process of currency internationalization. It is noteworthy that most studies are trying to measure the process of currency internationalization by measurement approach while rarely set up a mathematical model to study the process of currency internationalization, which may because many factors are involved in it and it is difficult to establish a clear model.

As an exploration, this paper attempts to establish a macroeconomic model of internationalization of the currency from the perspective of trade settlement structure. By constructing a model and the comparative static analysis of the model, to find out the factors that affect the structure of the trade settlement, which is logically the factors that affect the internationalization of the currency. Specifically, we have introduced two trade settlement structures, namely the import trade settlement structure and the export trade settlement structure. The former is embodied in the consumption of tradable goods (foreign goods) of the representative household, and the latter is reflected in the wages paid by the manufacturer which trade with the household. The higher the coefficient of settling in standard money in export and import trade, the higher the level of internationalization of this currency.

\section{MODEL AND ANALYSIS}

In order to simplify the processing without losing the generality, this paper constructs the macroeconomic model including the representative household, the enterprise and the government. The basic assumptions of the model are: the wage income of the representative household is derived from the manufacturer in the trade sector and the non-tradable sector, and their consumption expenditure is consumption of tradable goods and non-tradable goods; enterprises are divided into trade goods manufacturer and non-tradable goods manufacturer; the government keeps a break. 


\section{A. Representative household}

We assume that the utility of the representative household depends on the consumption of tradable goods and nontradable goods, which can be substituted for each other. Then the utility of the representative household in period $t$ is as follows:

$$
\begin{gathered}
U=\max _{\left\{c_{t+j}^{T}, c_{t+j}^{N}\right\}} \sum_{j=0}^{\infty} \frac{\beta^{j}}{1-\sigma}\left[\left(c_{t+j}^{T}\right)^{1-\sigma}+\right. \\
\left.\gamma\left(c_{t+j}^{N}\right)^{1-\sigma}\right]
\end{gathered}
$$

In the above equation, $\beta$ is the subjective discount rate; $\gamma$ is the selective preference of non-tradable goods for the tradable goods; $\sigma$ is the elasticity of marginal utility of the consumption.

The constraints of the representative household in period $t$ are:

$$
\begin{aligned}
& \quad\left[\theta_{t}+\left(1-\theta_{t}\right) e_{t}\right] h_{t} w_{t} L_{t}+\left(1-h_{t}\right) w_{t} L_{t}+ \\
& K_{t-1} r_{t}=\left[\varphi_{t}+\left(1-\varphi_{t}\right) e_{t}\right] c_{t}^{T}+c_{t}^{N}+K_{t}- \\
& (1-\delta) K_{t-1}
\end{aligned}
$$

In the budget constraint, $e_{t}$ represents the real exchange rate; $\theta_{t}, \varphi_{t}$ represent theratio of settlementin dollarin export and import trade respectively; hrepresents the ratio of absorption of the labor force by the tradable goods manufacturer; $w_{t}^{T}, w_{t}^{N}$ representthe wage rate of the household in the tradable goods manufacturer and non-tradable goods manufacturer; $r_{t}$ represents the return on capital.

We can find the first-order conditions:

$$
\begin{aligned}
& \frac{c_{t}^{T}}{c_{t-1}^{T}}=\left[\beta\left(1+r_{t}-\delta\right) \frac{\varphi_{t-1}+\left(1-\varphi_{t-1}\right) e_{t-1}}{\varphi_{t}+\left(1-\varphi_{t}\right) e_{t}}\right]^{\frac{1}{\sigma}} \\
& \frac{c_{t}^{N}}{c_{t-1}^{N}}=\left[\beta\left(1+r_{t}-\delta\right)\right]^{\frac{1}{\sigma}} \\
& \frac{c_{t}^{T}}{c_{t}^{N}}=\left\{\frac{1}{\gamma\left[\varphi_{t}+\left(1-\varphi_{t}\right) e_{t}\right]}\right\}^{\frac{1}{\sigma}}
\end{aligned}
$$

\section{B. Enterprise sector}

In order to analyze the trade settlement structure, we need to classify the enterprises: the manufacturer in trade sector and the manufacturer on-trade sector. For simplification, we assume that both the trade and non-trade sectors are injected by domestic capital and the capital and the labor are allocated to both of them proportionally.

Suppose that the manufacturer trade sector is constant to scale, and the production function can be written as:

$$
\mathrm{Y}_{\mathrm{t}}^{\mathrm{T}}=\mathrm{A}_{\mathrm{t}}\left(\rho_{\mathrm{t}} \mathrm{K}_{\mathrm{t}}\right)^{\alpha}\left(\mathrm{h}_{\mathrm{t}} \mathrm{L}_{\mathrm{t}}\right)^{1-\alpha}
$$

In the above equation, $\alpha$ is the elasticity of capital output. The profit function is:

$\pi_{t}^{\mathrm{T}}=\left[\theta_{\mathrm{t}}+\left(1-\theta_{\mathrm{t}}\right) \mathrm{e}_{\mathrm{t}}\right]\left[(1-\tau) \mathrm{y}_{\mathrm{t}}^{\mathrm{T}}-\mathrm{w}_{\mathrm{t}}^{\mathrm{T}} \mathrm{h} \mathrm{L}_{\mathrm{t}}\right]-\left(\mathrm{r}_{\mathrm{t}}+\delta\right) \rho \mathrm{K}_{\mathrm{t}}(7)$

Profit maximization with the condition (6), the first-order conditions can be derived:

$$
\begin{aligned}
& (1-\tau)(1-\alpha) \frac{Y_{t}^{T}}{h L_{t}}=w_{t}^{T} \\
& \alpha\left[\theta_{t}+\left(1-\theta_{t}\right) e_{t}\right](1-\tau) \frac{Y_{t}^{T}}{\rho K_{t}}=r_{t}+\delta
\end{aligned}
$$

Suppose that the manufacturer in non-trading sector has constant returns to scale, its production function can be written as:

$$
\mathrm{Y}_{\mathrm{t}}^{\mathrm{N}}=\mathrm{A}_{\mathrm{t}}\left[\left(1-\rho_{\mathrm{t}}\right) \mathrm{K}_{\mathrm{t}}\right]^{\alpha}\left[\left(1-\mathrm{h}_{\mathrm{t}}\right) \mathrm{L}_{\mathrm{t}}\right]^{1-\alpha}
$$

The profit function is:

$$
\pi_{\mathrm{t}}^{\mathrm{N}}=(1-\tau) \mathrm{Y}_{\mathrm{t}}^{\mathrm{N}}-\left(1-\mathrm{h}_{\mathrm{t}}\right) \mathrm{w}_{\mathrm{t}}^{\mathrm{N}} \mathrm{L}_{\mathrm{t}}-\left(\mathrm{r}_{\mathrm{t}}+\delta\right) \mathrm{K}_{\mathrm{t}}^{\mathrm{N}}
$$

Profit maximization and bring in (10), the first-order conditions can be derived:

$$
\begin{aligned}
& (1-\tau)(1-\alpha) \frac{\mathrm{Y}_{\mathrm{t}}^{\mathrm{T}}}{(1-\mathrm{h}) \mathrm{L}_{\mathrm{t}}}=\mathrm{w}_{\mathrm{t}}^{\mathrm{N}} \\
& \alpha(1-\tau) \frac{\mathrm{Y}_{\mathrm{t}}^{\mathrm{T}}}{(1-\rho) \mathrm{K}_{\mathrm{t}}}=\mathrm{r}_{\mathrm{t}}+\delta
\end{aligned}
$$

The government maintains a balance of fiscal revenue and expenditure, the decision equation is:

$$
G_{t}=\tau\left(Y_{t}^{N}+Y_{t}^{T}\right)
$$

\section{COMPARATIVE STATIC ANALYSIS OF THE MODEL}

In this part we analyze the comparative static analysis under equilibrium conditions. For simplification, we suppose international trade payments balance, and the equilibrium condition is:

$$
\mathrm{Y}_{\mathrm{t}}=\mathrm{C}_{\mathrm{t}}+\mathrm{I}_{\mathrm{t}}+\mathrm{G}_{\mathrm{t}}
$$

Under the equilibrium condition, the decision-making equations of each department in the whole economic system are:

$$
\begin{gathered}
\frac{c_{t}^{T}}{c_{t-1}^{T}}=\left[\beta\left(1+r_{t}-\delta\right) \frac{\varphi_{t-1}+\left(1-\varphi_{t-1}\right) e_{t-1}}{\varphi_{t}+\left(1-\varphi_{t}\right) e_{t}}\right]^{\frac{1}{\sigma}} \\
\frac{c_{t}^{N}}{c_{t-1}^{N}}=\left[\beta\left(1+r_{t}-\delta\right)\right]^{\frac{1}{\sigma}} \\
\frac{c_{t}^{T}}{c_{t}^{N}}=\left\{\frac{1}{\gamma\left[\varphi_{t}+\left(1-\varphi_{t}\right) e_{t}\right]}\right\}^{\frac{1}{\sigma}} \\
(1-\tau)(1-\alpha) \frac{Y_{t}^{T}}{h_{t} L_{t}}=w_{t} \\
\alpha\left[\theta_{t}+\left(1-\theta_{t}\right) e_{t}\right](1-\tau) \frac{Y_{t}^{T}}{\rho_{t} K_{t}}=r_{t}+\delta \\
(1-\tau)(1-\alpha) \frac{Y_{t}^{N}}{\left(1-h_{t}\right) L_{t}}=w_{t} \\
\alpha(1-\tau) \frac{Y_{t}^{N}}{\left(1-\rho_{t}\right) K_{t}}=r_{t}+\delta \\
G_{t}=\tau Y_{t} \\
Y_{t}=C_{t}+I_{t}+G_{t}
\end{gathered}
$$

by $(8),(9)$ :

$(1-\tau) Y_{t}^{T}=h_{t} w_{t} L_{t}+\frac{\left(r_{t}+\delta\right) \rho K_{t}}{\theta_{t}+\left(1-\theta_{t}\right) e_{t}}$

by(12), (13):

$(1-\tau) Y_{t}^{N}=\left(1-h_{t}\right) w_{t} L_{t}+\left(r_{t}+\delta\right)\left(1-\rho_{t}\right) K_{t}$

Add the above two types, we can get:

$\mathrm{Y}_{\mathrm{t}}=\frac{1}{1-\tau}\left[\mathrm{w}_{\mathrm{t}} \mathrm{L}_{\mathrm{t}}+\frac{(\mathrm{r}+\delta) \rho_{\mathrm{t}} \mathrm{K}_{\mathrm{t}}}{\theta_{\mathrm{t}}+\left(1-\theta_{\mathrm{t}}\right) \mathrm{e}_{\mathrm{t}}}+(\mathrm{r}+\delta)\left(1-\rho_{\mathrm{t}}\right) \mathrm{K}_{\mathrm{t}}\right]$ 
The changes of the degree of internationalization of the currency are discussed on three cases: the household, the manufacturer and the government. Specifically: when the attraction of foreign goods to the consumer becomes larger; when the flexibility of capital output becomes larger; when the fiscal expenditure of the government becomes larger.

\section{A. When foreign goods are more attractive to consumers, i.e.} when $\gamma$ becomes larger.

Other parameters unchanged, then by (4) we could know that the domestic consumption of good won't change accordingly. As $\gamma$ becomes smaller, combined with (3) (5) we can see that the consumption of foreign goods will become greater, i.e. $\varphi_{t}+\left(1-\varphi_{t}\right) e_{t}$ must become smaller. When the actual exchange rate is greater than 1,i.e. $e_{t}>1, \varphi_{t}$ becomes larger and the degree of internationalization of the currency is deepened; whene ${ }_{t}<1, \varphi_{t}$ becomes smaller, and the degree of internationalization of the currency is weakened; When $e_{t}=1$, the degree of internationalization of the money remains unchanged. According to the exchange rate theory, the actual exchange rate is greater than 1 which indicates that the local currency at this time is relatively undervalued. For the sake of convenience, we only discuss the condition that the actual exchange rate is greater than 1.If the actual exchange rate is less than 1, it will lead to an opposite conclusion. The conclusion is that if the local currency is undervalued, foreign goods will become more attractive, and the degree of internationalization of the currency will be deepened.

The economic meaning is: when the attractiveness of foreign goods to the consumer becomes larger, because of the local currency's undervaluation, the consumer prefers to settle in dollars when purchasing foreign goods. The function of medium of exchange of the currency becomes stronger, which makes the degree of internationalization the country's currency deeper.

\section{B. When the elasticity of the capital output becomes larger, i.e. when $\alpha$ becomes larger.}

From (16) (17) (18) we can see that the change of $\alpha$ does not affect the output at an equilibrium. As to (9), the output remains unchanged, while $\alpha$ becomes larger, $\rho_{\mathrm{t}}$ becomes smaller,and $\theta_{\mathrm{t}}+\left(1-\theta_{\mathrm{t}}\right) \mathrm{e}_{\mathrm{t}}$ becomes smaller. $\theta_{\mathrm{t}}+\left(1-\theta_{\mathrm{t}}\right) \mathrm{e}_{\mathrm{t}}=$ $\mathrm{e}_{\mathrm{t}}+\left(1-\mathrm{e}_{\mathrm{t}}\right) \theta_{\mathrm{t}}$, whene $\mathrm{t}>1, \theta_{\mathrm{t}}$ becomes larger and the degree of internationalization of the currency is deepened; When $\mathrm{e}_{\mathrm{t}}<1, \theta_{\mathrm{t}}$ becomes smaller, the degree of internationalization of the currency is weakened; when $e_{t}=1$, the degree of internationalization of currency remains unchanged. Thus, if the local currency is undervalued and production is more dependent on capital, the degree of internationalization of the currency becomes deeper.

\section{When the financial expenditure $\mathrm{G}_{\mathrm{t}}$ suddenly increases (such as military expenditure, earthquake relief, etc.).}

Suppose the remaining parameters unchanged, from (4) we can see the consumption of non-tradable goods does not change if the import trade settlement structure remains unchanged; from (3) we can see the total consumption remains unchanged if the consumption of trade goods does not change; from (15) we can see, if short-term output unchanged, consumption unchanged, and fiscal spending increased, then the investment decreases. For $\mathrm{I}_{\mathrm{t}}=\mathrm{K}_{\mathrm{t}}-(1-$ $\delta) \mathrm{K}_{\mathrm{t}-1}, \mathrm{~K}_{\mathrm{t}}$ becomes smaller. Based on (16) we can see, $\mathrm{G}_{\mathrm{t}}=$ $\frac{\tau}{1-\tau}\left[\mathrm{wL}+\frac{(\mathrm{r}+\delta) \rho \mathrm{K}_{\mathrm{t}}}{\theta_{\mathrm{t}}+\left(1-\theta_{\mathrm{t}}\right) \mathrm{e}_{\mathrm{t}}}+(\mathrm{r}+\delta)(1-\rho) \mathrm{K}_{\mathrm{t}}\right]$. Here, $\theta_{\mathrm{t}}+$ $\left(1-\theta_{\mathrm{t}}\right) \mathrm{e}_{\mathrm{t}}$ must become smaller. $\theta_{\mathrm{t}}+\left(1-\theta_{\mathrm{t}}\right) \mathrm{e}_{\mathrm{t}}=\mathrm{e}_{\mathrm{t}}+$ $\left(1-e_{t}\right) \theta_{t}$, when $e_{t}>1, \theta_{t}$ becomes bigger, the degree of internationalization of the currency is deepened; when $e_{t}<1$, $\theta_{t}$ becomes smaller,the degree of internationalization of the currency is weakened; when $e_{t}=1$, the degree of internationalization of the currency remains unchanged. The above can be concluded that if the real exchange rate of the local currency is greater than 1, then when the fiscal expenditure increases, the utilization ratio of the local currency in the export trade settlement becomes larger, and the degree of internationalization of the currency becomes deeper.

\section{CONCLUSIONS AND POLICY RECOMMENDATIONS}

The process of internationalization of the currency is relatively complicated economic phenomenon. There are many factors that affect the internationalization process. Therefore, the key of the interpretation of the process of currency internationalization is the choice of angle. From U.S.D dollar, Japanese yen to RMB, their internationalization process has their own unique influencing factors but also have some reasons in common. This paper studied it from a theoretical point of view, rather than the perspective of historical data and measurement, so the conclusion is not for a certain currency, but for commonalities.

This paper argues that there are at least three common factors that affect the internationalization of the currency: when the local currency is undervalued, the increase of the attractiveness of foreign goods, the elasticity of capital output and the government expenditure will deepen the degree of the internationalization of the currency; When the local currency is overvalued, the increase of the attractiveness of foreign goods, the elasticity of capital output and the government expenditure will weaken the degree of the internationalization of the currency.

Because they are commonalities, may wish to take the RMB for example to explain the process of currency internationalization.

"Report on Internationalization of RMB 2016" pointed out that the degree of internationalization of RMB in recent years has been deepened. Many scholars explain from the aspect of institutional changes and the background of globalization: the overall economic stability, financial reform in an orderly manner, the policy of cross-border RMB transaction under capital account taking further steps, the gradual improvement of infrastructure of RMB, China-EU economic and financial cooperation and so on.

- On the basis of this paper, we examine the process of internationalization of RMB from the perspective of trade settlement structure. Combining with the reality of China and the conclusion of this paper, the possible explanations of internationalization of RMB are:

- With the continuous deepening of the degree of openness, a large number of nationals travel, shop and consume abroad, the attractive of foreign goods on 
domestic consumers becomes greater, according to the first conclusion of this article, which will lead to the degree of internationalization of the RMB deepened.

- The transition of China's production mode from laborintensive to capital-intensive, i.e. the increase of flexibility of capital output, by the second conclusion of this article, which will lead to the deepening of the internationalization of the RMB

- A radical fiscal policy implemented in China in recent years, such as fiscal expenditure, by the third conclusion of this paper, the degree of internationalization of the RMB will be deepened.

Because of the complexity of currency internationalization, this paper attempts to introduce the trade settlement structure into our model to analyze the process of internationalization of money. Future research can be done form more variable perspectives.

\section{REFERENCES}

[1] Cohen B J. future of sterling as an international currency [M], Macmillan Press ,1971.
[2] Hartmann P. Currency competition and foreign exchange markets: the dollar, the yen and the euro[M]. Cambridge University Press, 1998.

[3] Pollard P S. The Creation of the Euro and the Role of the Dollar in International Markets[J]. REVIEW-FEDERAL RESERVE BANK OF SAINT LOUIS, 2001, 83(5): 17-36.

[4] Eichengreen B, Mathieson D J. The Currency Composition of Foreign Exchange Reserves; Retrospect and Prospect[R]. International Monetary Fund, 2000 .

[5] Kenen P B. The euro versus the dollar: will there be a struggle for dominance?[J]. Journal of policy modeling, 2002, 24(4): 347-354.

[6] Kenen P. The Euro and the Dollar: Competitors or Complements?[J]. The European Union and the United States, 2003: 251-74.

[7] Lim E G. The Euro's challenge to the dollar: different views from economists and evidence from COFER (Currency Composition of Foreign Exchange Reserves) and other data[J]. 2006.

[8] Chinn M D, Frankel J A. The euro may over the next 15 years surpass the dollar as leading international currency[R]. National Bureau of Economic Research, 2008.

[9] Thimann C. Global Roles of Currencies [J]. International Finance, 2008, 11(3): 211-245.

[10] Xiaoyan Bai,MingmingDeng. An Empirical Analysis on Influential Factors and Mechanism of Currency Internationalization.[J]. The Journal of Quantitative \& Technical Economics,2013,v.3012 pp:113-125. In Chinese) 